\title{
Compassos e descompassos do planejamento e da política de turismo no estado de Goiás (1991 a 2014)
}

Matches and mismatches of the planning and policy of tourism in the state of Goiás - Brazil (1991 to 2014)

Avances y retrocesos de la planificación y de la política de turismo en Goiás (1991-2014)

http://dx.doi.org/10.18472/cvt.18n3.2018.1362

Giselia Lima Carvalho 〈 giselialimacarvalho@gmail.com > Instituto Federal de Goiás (IFG), Campus Goiânia, Goiânia, GO, Brasil.

\begin{abstract}
1 Artigo resultante das discussões levantadas na tese de doutorado da autora intitulada "A política de turismo no estado de Goiás: um estudo sobre as escalas institucionais de intervenção", orientada pelo professor Eustógio Wanderley Correia Dantas e auxiliada com recursos da Fundação de Amparo à Pesquisa do Estado de Goiás (Fapeg) em parceria com a Capes, no Programa de Geografia da Universidade Federal do Ceará (UFC).
\end{abstract}

CRONOLOGIA DO PROCESSO EDITORIAL

Recebimento do artigo: 17-nov-2016

Aceite: 11 -jun-2018

FORMATO PARA CITAÇÃO DESTE ARTIGO

CARVALHO, G. L. Compassos e descompassos do planejamento e da política de Turismo no estado de Goiás (1991 a 2014). Caderno Virtual de Turismo. Rio de Janeiro, v. 18, n. 3, p. 123-138, dez. 2018.

REALIZAÇÃO

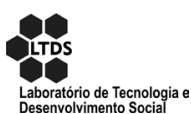

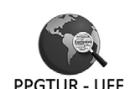

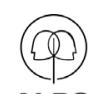

IABS
APOIO INSTITUCIONAL

COPPE

UFRJ

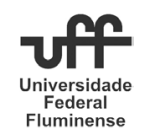

EDIÇÃO

PATROCÍNIO

EDITOR日

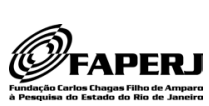




\section{RESUMO}

Este artigo pretende completar uma análise já realizada outrora ${ }^{2}$ sobre o processo histórico de constituição da política de turismo no estado de Goiás. O recorte que se priorizou compreende os anos de 1991 a 2014, envolvendo as gestões dos governadores Iris Rezende, Maguito Vilela, Marconi Perillo e Alcides Rodrigues. Mais que relacionar a política estadual às diretrizes da política nacional, importa tratar de como esses diferentes governos assimilaram a atividade turística no estado e como ela foi sendo traduzida em um período reconhecido como aquele que registrou os maiores avanços no âmbito do planejamento turístico brasileiro.

Palavras chave: Política estadual de turismo. Planejamento. Estado de Goiás.

\section{ABSTRACT}

This articles aims to complete an analysis already made once (CARVALHO, 2015) about historical process of the constitution of the policy of tourism in the state of Goiás. The time cutout from 1991 to 2014 involves the management of the governors Iris Rezende, Maguito Vilela, Marconi Perillo and Alcides Rodrigues. More than relate the state policy to the national policy guidelines, it matters to treat how these governments assimilated the tourism activity in the state and how it was being translated in a period recognized as the one that registered the major progresses in the scope of the planning of Brazilian tourism.

Keywords: State policy of tourism. Planning. State of Goiás.

\section{RESUMEN}

Este artículo tiene la intención de completar un análisis realizado en outro trabajo (CARVALHO, 2015) que analiza el proceso histórico de formación de la política de turismo en el estado de Goiás (Brasil). El marco de tiempo abarca los años 1991-2014, correspondiente a las gestiones de los gobernadores Iris Rezende, Maguito Vilela, Marconi Perillo y Alcides Rodrigues. Más que hacer una investigación entre la política estatal y la política nacional, es importante tener en cuenta cómo estos diferentes gobiernos han asimilado la actividad turística en el estado y cómo esta actividad fue traducida en un período reconocido cómo el que ha registrado los mayores avances en el ámbito de la planificación del turismo brasileño.

Palavras clave: Política estadual de turismo. Planificación. Estado de Goiás.

\section{INTRODUÇÃO}

Uma das características do processo de constituição da atividade turística no Brasil é a sua estreita relação com as ações de cunho público-governamental, aliada à expectativa quanto aos seus desdobramentos sobre os territórios turísticos locais. Tendo em vista essas máximas, este artigo esforça-se para compreender o processo histórico que engendrou a política de turismo no estado de Goiás, articulando as escalas de intervenção federal, estadual e municipal. Para essa investida, priorizou-se o recorte temporal entre 1991 e 2014, percorrendo as gestões de quatro governadores estaduais, de modo a verificar como se deu a participação do ator Estado e o modo como os diferentes governos assimilaram a atividade turística no estado de Goiás.

\footnotetext{
2 A análise que antecede a esta está publicada no Boletim Goiano de Geografia, v. 35, n. 3, p. 507-529, set./dez. 2015, sob o título “Mapeamento e trajetória político-institucional do turismo no estado de Goiás entre 1961 e 1990 ".
} 
Com o intuito de identificar claras e tácitas evidências de ações que concorreram para edificar uma agenda de preocupações para o turismo conduzida pela mão do poder público, a pesquisa pautou-se no levantamento da legislação goiana voltada para o turismo e na identificação e análise dos planos e programas voltados para o turismo estadual e no diagnóstico dos investimentos para o setor.

A análise percorre uma trajetória de um pouco mais de duas décadas do processo de constituição da política do turismo goiano. Basicamente delimitado por três períodos, discute-se, primeiramente, a política estadual ressaltando a efervescência do processo de descentralização do turismo e do debate ambiental. Na sequência, procura-se demonstrar um importante momento da política no estado, cuja ferramenta do planejamento teve seu maior esplendor, estimulado pela exigência do chamado PPA (Plano Plurianual). Com o avançar da análise, verifica-se um processo de avanços e retrocessos, de compassos com a política nacional e de descompassos em relação à intencionalidade da política de turismo, verificando-se, nos anos mais recentes, uma perda de papel e de norteamento do órgão máximo do planejamento do turismo no estado. Nessa trajetória de não linearidade do planejamento do turismo goiano, uma tese se confirma: o turismo goiano, no contexto nacional, ainda está à margem, com peso econômico sutil, e, quando posto no contexto da própria economia do estado, não é capaz de concorrer com as atividades produtivas ligadas à indústria, à agricultura e à pecuária.

\section{A POLÍTICA DE DESCENTRALIZAÇÃO DO TURISMO E A TÔNICA AMBIENTAL (1991-1998)}

Para a política de turismo no Brasil, a década de 1990 representou um marco regulatório, após a redefinição do papel do Instituto Brasileiro de Turismo (Embratur) e de sua responsabilidade na execução de uma política nacional setorial. É a partir daqui que se começa a pensar em políticas públicas para o turismo, conforme defende Cruz (2000). Em sintonia com o melhor desempenho das diretrizes nacionais, algumas mudanças repercutiram também no estado de Goiás.

No referido contexto, o então governador Iris Rezende (1991-1994), sob o estímulo do Plano de Desenvolvimento da Região Centro-Oeste (BRASIL, 1986), da Superintendência de Desenvolvimento do Centro-Oeste - Sudeco, tenta aumentar o fluxo de recursos e de financiamentos para projetos turísticos nos estados e funda a Diretoria de Turismo ${ }^{3}$ com ações bastante pontuais como um fundo especial destinado à construção do Centro de Cultura e Convenções Dona Gercina Borges Teixeira, atual Centro de Cultura e Convenções de Goiânia.

Animado pela tônica ambiental vivida no mundo após a Eco-92, constituiu-se uma comissão para conduzir, gerenciar e apreciar o Zoneamento Ecológico-Econômico do Estado de Goiás, ${ }^{4}$ considerando a "imensa riqueza e a enorme importância do bioma do Cerrado, que ocupa a quase totalidade do território goiano” (GOIÁS, 1993). Aliás, o setor turístico, na década de 1990, energizou-se pela questão ambiental mundial e nacional que atingiu a escala dos estados e colocou em evidência as regiões Centro-Oeste e Norte, dado o potencial ecológico de ambas. No caso de Goiás, Almeida (2002) aponta dois projetos de

3 Lei no 11.655 , de 26 de dezembro de 1991 (GOIÁS, 1991).

4 Esse mesmo documento foi reapresentado no governo de Maguito Vilela via Decreto no 4.496, de 18 de julho de 1995 (GOIÁS, 1995b), o que demonstra a não exequibilidade do primeiro. 
maior envergadura para a consolidação do turismo: o Projeto de Execução Descentralizada (PED), que instituiu os Polos de Ecoturismo, e a atuação do Sebrae na promoção de atividades diversas pertinentes ao turismo.

Considera-se o PED uma das estratégias de descentralização da Política Nacional do Meio Ambiente nos estados que representou a primeira experiência de desenvolvimento sustentável do governo brasileiro e se efetivou no estado de Goiás por meio dos chamados Polos Irradiadores de Ecoturismo Microrregional. Os municípios beneficiados (Alto Paraíso de Goiás, Pirenópolis, São Domingos e Três Ranchos) foram contemplados por um vasto plano de ações que envolviam diagnóstico, formatação de produtos, organização institucional local, regulamentação, capacitação e, sobretudo, medidas de proteção ao patrimônio, executadas entre 1994 e 1998. Este período compreendeu a gestão do governador Luiz Alberto Maguito Vilela (1995-1998), quando, exatamente, constatou-se um arrefecimento no turismo por parte da iniciativa do governo estadual.

No diagnóstico levantado, assiste-se a um descompasso na política turística e ambiental entre os níveis federal e estadual. Quanto às mudanças organizacionais administrativas, o governador tomou uma medida que depreciava ainda mais a função do órgão oficial de turismo: a Empresa de Turismo do Estado de Goiás $(\text { Goiastur })^{5}$ deu lugar à Empresa Estadual de Eventos e Promoções, órgão máximo do turismo goiano. Com base nos dados levantados, essa empresa atentaria mais para a promoção de eventos e convenções que propriamente para o planejamento e desenvolvimento do setor como um todo, sem mostrar uma preocupação explícita com a Política Estadual de Turismo. Conforme estipulado no objetivo desse novo órgão, caberia a ele

[...] fomentar o desenvolvimento do turismo no estado de Goiás, bem como o processo socioeconômico, cultural e técnico-científico, atraindo para os municípios goianos e sediando, em suas dependências, convenções, feiras, exposições, congressos, seminários, conferências e outros eventos de caráter local, regional, nacional e internacional, atendendo particularidades setoriais de acordo com a estrutura e vocação de cada município. (GOIÁS, 1995a).

De fato, a opção de desenvolver o turismo no estado foi da política de "promoção", sobretudo sem a devida coordenação de um plano. Nessa linha, uma intervenção verificada foi a efetivação do Centro de Cultura e Convenções Dona Gercina Borges Teixeira, em Goiânia, onde já se concentravam mais de um milhão de habitantes (INSTITUTO BRASILEIRO DE GEOGRAFIA E ESTATÍSTICA, 1996) e um setor de serviços, negócios e eventos em evidência - isso pode justificar a opção de criar a Empresa Estadual de Eventos e Promoções, que parecia existir em função da cidade de Goiânia.

No primeiro Plano Plurianual - 1996/1999 (GOIÁS, 1996), referente a essa gestão, consta o montante de $\mathrm{R} \$ 71.300 .000,00$ para atender aos objetivos de:

- Elaborar o Anuário Turístico de Goiás;

- Elaborar estudos para dotar as áreas verdes de infraestrutura;

- Apoiar as festas religiosas, Rio Araguaia e o Carnaval temporão;

- Implantar terminais turísticos nas cidades-polos;

- Implantar albergues da juventude;

\footnotetext{
5 Na administração do governador Leonino Caiado, em 1972, foi definida, à luz do contexto nacional, a Política Estadual de Turismo, que criou o Conselho Estadual de Turismo (Contur) e a Empresa de Turismo do Estado de Goiás (Goiastur), vinculada à Secretaria da Indústria e Comércio, com natureza de empresa pública e a finalidade de executar a Política Estadual de Turismo, conforme a Lei ${ }^{\circ}$ 7.540, de 12 de setembro de 1972.
} 
- Implantar pórticos de entradas nas cidades turísticas;

- Capacitar as empresas de turismo;

- Construir o polo estadual de Cachoeira Dourada e Buriti Alegre;

- Divulgar o turismo goiano em nível nacional e internacional.

Na óptica federal, o programa implementado nos estados era o Programa Nacional de Municipalização do Turismo (PNMT), que foi desenvolvido em todos os estados brasileiros desde 1995 e se encerrou em 2001, sendo esta a principal ação para o desenvolvimento do turismo na gestão de Fernando Henrique Cardoso. Em 1999, foi criado o Comitê Executivo do Estado de Goiás para o PNMT, com as finalidades de I - coordenar as ações de implantação do programa; II - acompanhar e avaliar o desenvolvimento dessas ações; III - coordenar a divulgação em nível estadual. ${ }^{6}$ De certo modo, os polos de ecoturismo tinham bastante relação com as ações desse programa, haja vista que representaram uma linearidade de intervenções nos municípios, asseguraram a continuidade de uma metodologia de descentralização das estratégias e foram executadas pelo mesmo agente, o Sebrae (EMBRATUR, 1999a).

Como o PNMT se baseava em adesão voluntária, o estado de Goiás contou com uma média de 70 municípios, classificados como Municípios Turísticos (MT) e Municípios com Potencial Turístico (MPT). Diga-se de passagem, uma conta alta, tendo em vista que a maioria desses municípios não havia alcançado nenhum estágio de preparação para o turismo. A participação estava relacionada a uma inscrição do município no programa e a seu interesse em atualizar ou não as informações que deveriam ser repassadas por meio dos Relatórios anuais do Rintur, não ao peso real que o turismo poderia representar no local. $\mathrm{O}$ conjunto dos mapas (Figura 1) mostra a evolução desse programa no estado, entre 1997 e 2002.

6 Por meio do Decreto nº 5.049, de 18 de maio de 1999 (GOIÁS, 1999a). 


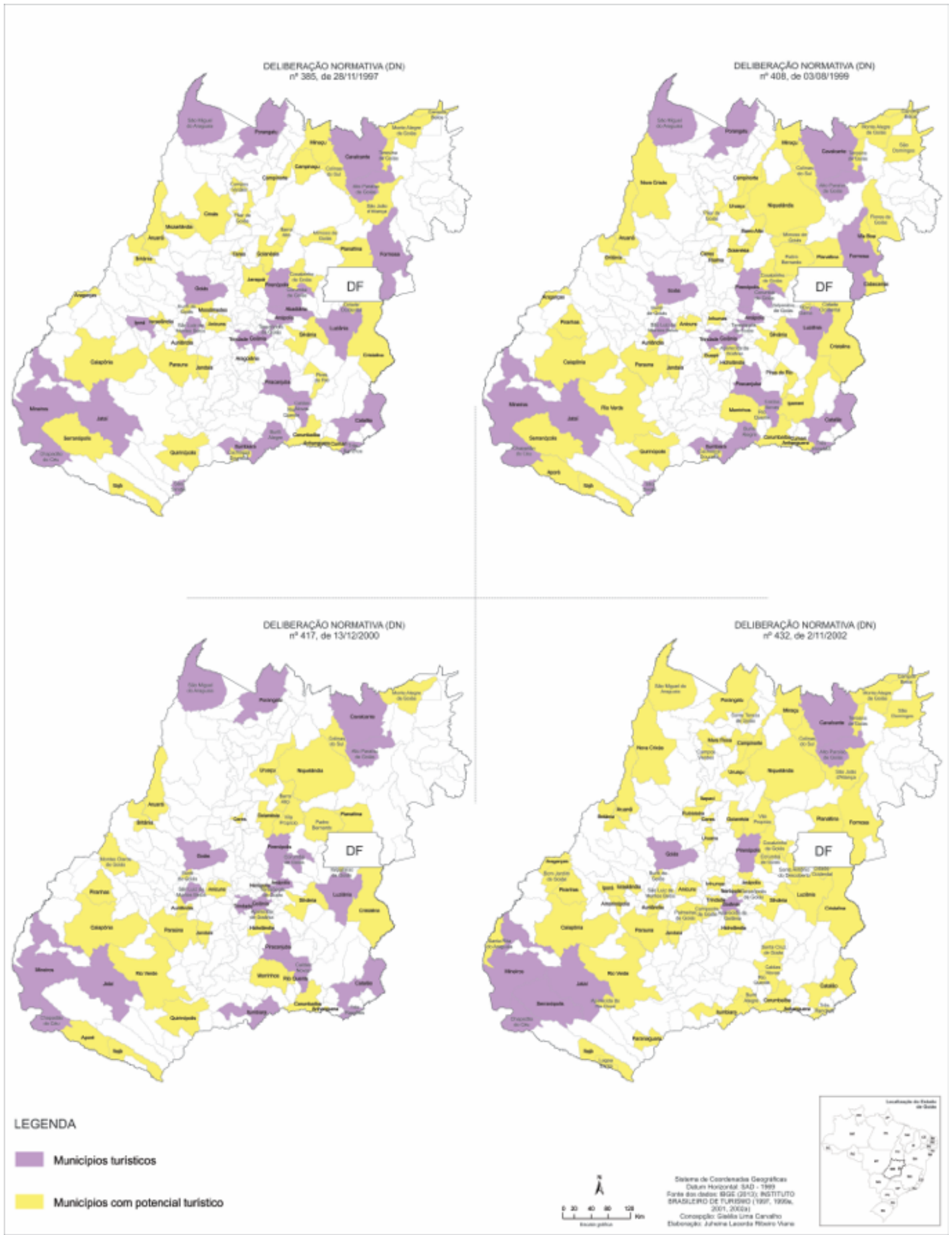

Figura 1 - Política de turismo no estado de Goiás: Programa Nacional de Municipalização do Turismo (PNMT) - 1997 a 2002

Fonte: Embratur (1997, 1999b, 2000 e 2002). 
Os frutos do PNMT em Goiás foram essenciais para a importância do turismo no estado, sobretudo quanto à autonomia dos municípios turísticos, que adotaram outra natureza de gestão. Adicionalmente, ocorreu maior socialização das informações, o que permitiu maior exequibilidade de mensuração de impactos das políticas em todos os setores. Segundo Flávia de Brito Rabelo, então gerente de Planejamento e Pesquisa da Agência Estadual de Turismo (Agetur), o PNMT é considerado um programa bem relevante para o estado de Goiás. Ela assinalou a importância de um plano que fortalecesse a gestão política e que criasse uma governança local, fundamental para as próximas etapas do planejamento. Do ponto de vista da gestão política, o PED e o PNMT foram os embriões do Programa de Regionalização do Turismo (PRT). Na opinião de João Lino, gerente de Projetos de Produtos Turísticos da Goiás Turismo: "A política foi disponibilizada pra todo mundo, mas quem soube trabalhar, amadureceu como destino".

\section{O FORTALECIMENTO DO PLANEJAMENTO NA ESFERA ESTADUAL E MUNICIPAL (1999-2010)}

Embora tenha sido feita uma referência ao Plano Plurianual 1996/1999, este representou um mero ensaio para o planejamento do estado de Goiás, uma vez que não foi disponibilizado ao público, já que não foi votado. Pode-se afirmar que as experiências mais frutíferas de gestão e planejamento via PPA em Goiás se deram nas duas gestões consecutivas de Marconi Ferreira Perillo Júnior (1999-2006). ${ }^{7}$ Como afirma Salgado (2010), somente no final da década de 1990 é que esse modelo de intervenção regional, baseado nas diretrizes do planejamento estratégico, passou a integrar a agenda de preocupação do governo estadual.

Diversos fatores atrelados a essas duas gestões do governo de Marconi Perillo levam-nos a julgá-lo particular quanto ao tratamento da política turística no estado, entre eles: a) a efetiva adoção de uma ferramenta de planejamento com traçados mais claros (PPA); b) a sequência de gestão que, grosso modo, asseguraria maior possibilidade de continuidade dos programas e c) a existência de um contexto jamais visto de gestão nacional do turismo, considerando a criação do MTur em 2003.

A marca da administração desse gestor é a renovação na forma de governar. Assim, ele tratou de reorganizar toda a estrutura administrativa do Estado na tentativa de modernizá-lo. No tema que nos interessa, muitas transformações ocorreram no sentido de extinguir ou redefinir órgãos criados pelos governos anteriores. Um dos exemplos foi a transformação, em 1999, da Empresa Estadual de Eventos e Promoções na Agetur. ${ }^{8}$ Algumas dessas mudanças parecem ter favorecido o turismo, com a recriação de um órgão estadual próprio e com função ampliada, o que indicou uma política estadual para o setor:

Art. $2^{\circ}$ - É missão da Agetur propiciar o fortalecimento e crescimento do turismo do Estado de Goiás, visando intensificar sua contribuição para geração de renda, ampliação do mercado de trabalho, elevação dos padrões do bem-estar social, integração nacional e valorização do patrimônio natural, cultural e técnico-científico. (GOIÁS, 1999b).

A situação vivida pelo turismo em todo o País era ainda de intensa mobilização dos estados para a inserção de seus municípios no PNMT. O governo de Goiás criou, nesse contexto, o Comitê Executivo do

7 Perillo ainda retornou para outros dois mandatos, em 2011 e 2014, completando 16 anos à frente da gestão do governo estadual. 8 Entidade autárquica criada pela Lei no 13.550 , de 11 de novembro de 1999 (GOIÁS, 1999C), e regulamentada pelo Decreto no 5.090 , de 20 de agosto de 1999 (GOIÁS, 1999b). 
Estado de Goiás para o acompanhamento do programa (GOIÁS, 1999a), ${ }^{9}$ e assim definiu a Política Estadual de Turismo como "o conjunto de diretrizes e normas ligadas ao planejamento e à execução das iniciativas públicas, particulares e da sociedade organizada, concernentes ao turismo, desde que interessem ao desenvolvimento econômico, social e cultural do Estado de Goiás" que deveria ser "orientada de maneira sistêmica e harmônica com a Política Nacional de Turismo" (GOIÁS, 2000a). ${ }^{10}$

No contexto de seu planejamento global estratégico, o primeiro plano da gestão de Marconi Perillo foi o Plano Plurianual 2000/2003: Goiás século XXI, ${ }^{11}$ cujo objetivo geral era a "inserção de Goiás na economia nacional e internacional para garantir seu crescimento em termos de progresso econômico, social e de qualidade de vida" (GOIÁS, 1999d). Essa abordagem se refletiu, no âmbito do turismo, em seis modalidades de programas com orçamento próprio de $\mathrm{R} \$ 117.649 .920,00$ para o exercício, os quais indicaram o fortalecimento da política de turismo no estado, com proposição de seis (6) Programas de Desenvolvimento Turístico para as regiões já definidas pelo Mtur.

Nessa perspectiva, verifica-se uma diferença crucial quanto ao processo de planejamento estratégico estatal, que promoveu ações mais bem definidas, com programas e orçamentos específicos e de dimensão mais ampla, considerando a diversidade do estado sob a denominação de "polos". Um ponto a destacar do referido PPA é que alguns municípios, considerados polos turísticos, receberam maior atenção por parte dos programas, sem desconsiderar a necessidade de estimular e desenvolver as vocações de outros municípios.

Na segunda gestão de Marconi Perillo, o Plano Plurianual 2004/2007: Plano Goiás século XXI - Avançar Mais, constituído por seis macroestratégias não setorizadas nos órgãos de planejamento do estado, inseriu o turismo no polo Goiás Competitivo e Polo Econômico Regional. Um dos desafios do plano era desenvolver a competitividade goiana por meio de estratégias que potencializassem as forças econômicas do estado, com sólida superação dos entraves ao seu desenvolvimento e aprofundamento da modernização administrativa. Todavia, dada a inserção dos temas de inclusão social no Brasil, o plano também destacava a importância da redução das desigualdades sociais, por meio da formulação e implementação de políticas que assegurassem vida digna para todos.

Sob o favorecimento do recém-criado MTur, a temática ambiental, melhor dizendo, a sustentabilidade teve maior trânsito em todo o País, o que não foi diferente para o estado de Goiás, em que o resultado foi a instituição da Política de Desenvolvimento do Ecoturismo e do Turismo Sustentável no Estado de Goiás, ${ }^{12}$ destinada aos territórios onde havia recursos naturais e patrimônio cultural que fossem objeto de visitação e turismo, sob responsabilidade do Poder Executivo, em parceria com as prefeituras municipais.

Quanto ao aspecto específico aqui tratado, dois programas marcam esse plano. O Programa Mostra Goiás tinha como escopo “[p]romover o estado em nível regional, nacional e internacional, transformando Goiás em um dos principais destinos turísticos e gerando emprego e renda para as comunidades envolvidas no processo" (GOIÁS, 2003). O Programa Infraestrutura Turística, por sua vez, objetivava "oferecer infraestrutura turística adequada a cada região de forma a atender às necessidades de orientação e conforto dos visitantes e da comunidade" (GOIÁS, 2003), e suas principais ações incluíam a implantação do Centro de Convenções em Caldas Novas e de centros culturais, como a Vila Cultural Teatro Goiânia e o

\footnotetext{
9 Decreto $\mathrm{n}^{0} \mathbf{5} .049$, de 18 de maio de 1999.

10 Decreto $n^{\circ} 5.300$, de 18 de outubro de 2000 (GOIÁS, 2000a).

11 Lei Complementar no $13 \cdot 570$, de 28 de dezembro de 1999 (GOIÁS, 1999d).

12 Lei no 14.769, de 12 de maio de 2004 (GOIÁS, 2004).
} 
Museu Internacional Art Dèco e Centro Cultural Oscar Niemeyer, todos inseridos no orçamento de 2005. As ações, que constavam no exercício do referido PPA, com orçamento previsto de R $139.634 .325,00$, foram executadas, exceção feita ao Museu Internacional Art Dèco.

Já em relação às intervenções federais, foi celebrado um convênio entre Agetur e MTur a fim de descentralizar as ações para a execução do Programa de Qualificação dos Serviços Turísticos. Esse convênio só veio a ser executado na gestão do governador Alcides Rodrigues Filho (2007-2010), já que teve contrato firmado por cinco anos. O PPA 2008/2011 (GOIÁS, 2008b) ${ }^{13}$ tinha a orientação para um projeto de desenvolvimento que culminasse em um Estado de Qualidade de Vida, conforme se extrai do documento. Na proporção inversa aos anteriores, mas seguindo as diretrizes nacionais, o plano pretendia reafirmar o planejamento como condutor do desenvolvimento social e regional e como indutor do crescimento econômico.

Em uma abordagem mais voltada para o nosso objeto, pode-se dizer que o principal instrumento estratégico que mais se aproximava da política estadual para o desenvolvimento do turismo em Goiás foi a elaboração do primeiro e único Plano Estadual de Turismo, em 2007, alinhado às diretrizes do Plano Nacional de Turismo 2007/2010: uma viagem à inclusão. No Plano Estadual de Turismo: Goiás no caminho da inclusão (GOIÁS TURISMO, 2007), as nove regiões turísticas foram mantidas e 46 municípios foram definidos, segundo os critérios de classificação nacionais. Para cada uma dessas regiões, o plano traçou diretrizes de diferentes graus e necessidades de intervenção e agentes responsáveis, respeitando as especificidades e os níveis de desenvolvimento da atividade em cada município. Após o PNMT, a filosofia em voga era a de regionalização do turismo, com a continuidade das ações descentralizadas. Subentendese que o PNMT foi uma preparação importante para os municípios turísticos e que estes, a partir de então, deveriam ser organizados por regiões contempladas nas políticas de escalas nacional e subnacional.

No âmago das regiões, os municípios foram classificados como "diamante", "esmeralda" e "cristal". A prioridade das políticas deveria ser aqueles municípios com maior grau de turistificação, dado o potencial reconhecidamente existente e as ações ocorridas desde o governo de Mauro Borges Teixeira (1961-1964), quando se verificou as primeiras intervenções estatais ordenadas por meio de um plano com objetivos e metas que incluíram o turismo.

Fato novo na história do turismo goiano, contido nas diretrizes estaduais, foi o estímulo à pesquisa sobre o turismo que se seguiu à criação do Instituto de Pesquisas Turísticas do Estado de Goiás (IPTur) ${ }^{14}$, instituído com o objetivo de implantar um sistema de informação turística baseado na organização e geração de dados, análises e estudos estratégicos de forma continuada, conforme consta em seu site.

A Agetur teve uma nova alteração de nomenclatura e de função. Agora com a denominação de Goiás Turismo, o órgão passou a ter um papel aparentemente mais amplo, de concepção mais sistêmica e com capacidade de enxergar e mensurar a diversidade do estado. Sua responsabilidade foi assim definida:

[...] execução da política estadual de turismo, compreendendo identificação, desenvolvimento e exploração de potenciais turísticos do Estado; execução de ações relacionadas com o turismo; captação de recursos; prestação de serviços técnicos, monitoramento de impacto socioeconômico, ambientais, culturais e qualificação de profissionais relacionados com turismo. (GOIÁS, 2011a, grifo nosso).

13 Lei no 16.193, de 29 de janeiro de 2008 (GOIÁS, 2008a). Revista pela Lei no 16.871, de 4 de janeiro de 2010 (GOIÁS, 2010a). 14 Lei n-16.828, de 11 de dezembro de 2009 (GOIÁS, 2009). 
A Política Estadual de Turismo, por sinal, em boa parte da sua trajetória, pôde ter confirmada uma vinculação com a matriz nacional, embora sem o reforço de grandes programas de financiamento. Do ponto de vista orçamentário, mesmo com a criação do MTur em 2003, o turismo goiano foi mais impactado a partir de 2008, tendo significativos avanços no aumento dos recursos em 2010, 2011 e 2013, consoante às informações da Sefaz/GO (GOIÁS TRANSPARENTE, [2015]). Em 2008, os recursos estaduais destinados ao turismo mais que quadruplicaram e continuaram a crescer nos anos seguintes, chegando a ultrapassar 170 milhões de reais em 2013, conforme revela a Figura $2^{15}$.

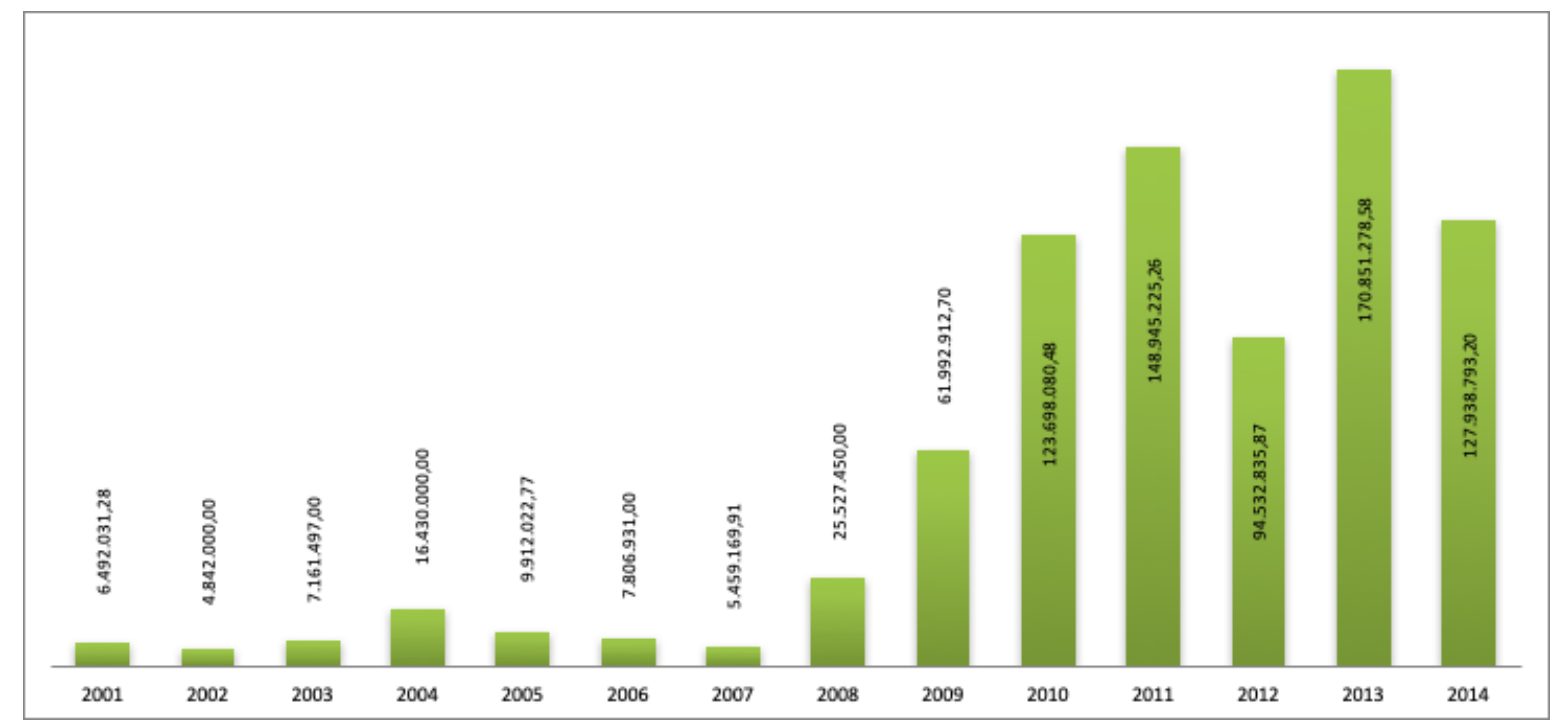

Figura 2 - Execução orçamentária em Reais do turismo pelo governo estadual (2001 a 2014)

Fonte: Goiás Transparente [2015].

Os impactos positivos, do ponto de vista político, nunca antes sentidos pelo setor do turismo no estado, podem estar associados, em âmbito geral, ao que Salgado (2010) apontou como a marca do PPA 2008/2011, ou seja, o aperfeiçoamento da prática de planejamento no estado, os avanços em relação à apresentação do documento e à participação dos municípios na elaboração e redefinição de prioridades de investimentos. Em pormenores, a alteração do quadro pode estar relacionada ao período da gestão do secretário estadual de Turismo Barbosa Neto, durante a qual não só aumentaram os recursos mas também foram lançados outros projetos, como a Casa do Turismo, a Vila Cultural e o Programa Nacional de Desenvolvimento do Turismo em Goiás (Prodetur Goiás), além da criação do IPTur. Para o representante da Goiás Turismo, João Lino, o fato está ligado à situação particular vivida pelo MTur nessa época: "Eu me lembro que em 2007 eu estava no MTur e aquele período registrou o maior orçamento da história do turismo, e começa a mostrar sua importância, assim como a atividade turística no País. Depois passou-se a restringir os recursos".

Nos moldes de outros programas existentes no Brasil, mas de natureza díspar de tudo antes projetado, o Prodetur Goiás, aprovado em 2010, ${ }^{16}$ deveria ser executado com recursos oriundos da Linha de Crédito Condicional (CCLIP), segundo contrato de empréstimo firmado entre o MTur e o BID, e transferidos

15 Segundo informações da Goiás Turismo, os recursos foram tantos nesse período que o órgão não conseguiu executá-los em sua totalidade.

16 Lei $\mathrm{n}^{0}$ 17.140, de 1ํㅡㄹ de setembro de 2010 (GOIÁS, 2010b). 
mediante contrato de empréstimo a ser celebrado entre o governo estadual e o BID. A operação de crédito externo contratado foi de até o limite de US\$ 80.000.000,00. A distribuição dos recursos entre o programa abrangeria cinco polos e 22 municípios, conforme os relatórios dos Planos de Desenvolvimento Integrado do Turismo Sustentável - Pdits.

Conforme declarações da coordenadora técnica, Cristiane Ricci Mancini, que esteve envolvida no programa desde que ele era só um projeto, em 2007, muitos fatores foram impeditivos para a execução do Prodetur Goiás, entre eles está o fato de o governo estadual não ter liberado o recurso referente à sua contrapartida ( $10 \%$ do valor do convênio para o governo estadual, 30\% para o MTur e $60 \%$ para o BID).

Situação semelhante ocorreu com o Programa Estadual de Incentivo à Aviação Regional (Voe Goiás), ${ }^{17} \mathrm{o}$ qual objetivava estimular a implantação e/ou expansão de linhas aéreas regionais e nacionais (domésticas) regulares, com a construção de 34 aeroportos estrategicamente localizados no estado de Goiás. No decreto ficou instituído que a Goiás Turismo cuidaria do programa. No entanto, iniciada a nova gestão, com o Plano de Ação Integrada de Desenvolvimento (PAI) 2012-2015 (GOIÁS, 2012), na terceira gestão de Marconi Perillo, a Agência Goiana de Transportes e Obras (Agetop) é que ficou responsável pela execução dessa política, reduzindo a importância do órgão oficial do turismo.

\section{A POLÍTICA DE EVENTOS E O ENFRAQUECIMENTO DA POLÍTICA DE PLANEJAMENTO TURÍSTICO ESTATAL (2011-2014)}

Pelo que foi constatado anteriormente, a terceira gestão de Marconi Perillo (2011-2014) não deu a devida atenção à pasta do turismo, além do fato de suas metas e programas terem sido redigidos sem o conhecimento da Goiás Turismo, segundo informações de representantes do órgão.

Esse e outros aspectos organizacionais e, acima de tudo, políticos, permitem-nos concluir que não só houve o enfraquecimento da Goiás Turismo, como também foi interrompido o desenvolvimento da política para o turismo no estado, desmanchando a própria política outrora delineada por ele mesmo. O reflexo disso é sentido na desmotivação do pessoal envolvido nas atividades de gestão nas escalas dos municípios turísticos, como pode ser notado no desabafo de um secretário de Turismo:

\footnotetext{
Posso dizer que as reuniões do fórum foram mais fortes antes de 2012. Era pra estar mais ativo [...]. É uma demanda do governo federal, mas a gente sente pouco apoio do governo estadual recentemente. Houve uma perda de importância do papel da Goiás Turismo, enquanto estrutura, houve uma decadência nos últimos dois, três anos (ele se refere a 2013-2015), com perda de pessoal, diga-se de passagem, um pessoal bem preparado. (entrevista com o secretário de Turismo de Pirenópolis, em março de 2015).
}

No entendimento do então gerente de Projetos de Produtos Turísticos da Goiás Turismo, João Lino, sobre o andamento da política nacional no estado, o desempenho do PRT funcionou muito bem entre 2003 e 2012. Em termos de planejamento, a política foi completa, mas em termos de se tornar produto, faltou fechar um ciclo.

Com a nova reestruturação administrativa promovida pelo Estado, ao que tudo indica, à Goiás Turismo ficou reservado o papel de executora da política de eventos. Fabiana Pulcineli (2013) trouxe

17 Decreto n- 7.351, de 25 de maio de 2011 (GOIÁS, 2011b). 
à tona no jornal $O$ Popular o montante de recursos que o governo do estado tem derramado sobre a categoria eventos, principalmente os shows de música sertaneja. ${ }^{18} \mathrm{Em} 2011$, conforme denuncia o jornal, foram gastos com shows R 7,5 milhões; em 2013 esse valor subiu para R 21,18 milhões e, somente nos primeiros sete meses de 2014, o estado, sob a coordenação da Goiás Turismo, já havia patrocinado 306 shows, alcançando o valor de R \$22,3 milhões. Em nossa busca no site do órgão, dos 58 convênios expostos ao público, fechados entre a Goiás Turismo e municípios ou instituições, todos foram exclusivamente destinados à realização de eventos. Tudo isso é plenamente justificável nas palavras do então secretário de Assuntos Estratégicos do estado de Goiás, Luiz Alberto de Oliveira:

O dinheiro do povo tem de ser gasto onde o povo deseja. Shows são reivindicações populares. Eles querem aquilo. Às vezes, mesmo que o governo esteja apertado, dá um jeito de atender, porque as pessoas também têm direito ao lazer (PULCINELI, 2013).

Admite-se que os eventos, na interescalaridade, passaram a assumir um papel de destaque no desenvolvimento turístico, configurando-se como uma das principais estratégias de promoção de destinos. Entretanto, a demasiada prioridade que o órgão passou a ter nos últimos anos, curvando-se para essa modalidade, reflete uma ausência de planejamento mais integral do turismo no estado, redundando na falta de uma política para o setor. Além disso, essa estratégia deliberada e orientada tem a ver com uma forma de fazer política conhecida por todos como a velha "política do pão e circo", alimentada pela falta de informação do povo romano que, não tendo interesse por assuntos políticos nem preocupação com suas reais necessidades, priorizava a diversão. Isso é seguramente o que vem ocorrendo no estado, pela mão da Goiás Turismo.

Convém anotar o que representou essa instituição ao longo do seu processo histórico. Mesmo que o turismo goiano não tenha feito parte do cartão-postal do destino Brasil, o governador Leonino Di Ramos Caiado $^{19}$ ousou ao fundar uma das primeiras secretarias estaduais para o setor no País, em 1972, à frente de outros estados considerados de alto potencial turístico, como Ceará, Rio Grande do Norte, Alagoas e Santa Catarina. ${ }^{20}$ Durante suas quatro décadas de existência, muitas transformações ocorreram, às vezes somente no âmbito da nomenclatura, mas, sobretudo, no que tange à redefinição de atribuições, à dimensão, retração ou ampliação de seu papel, o que refletiu em diferentes formas de tratar a atividade turística na agenda dos governos, aliadas ainda às frequentes mudanças político-partidárias e às crises político-econômicas, mormente na década de 1980. Permeada ora por avanços, ora por retrocessos, a trajetória não linear de representação desse organismo público estadual seguramente afetou o desempenho da política de turismo no estado, a exemplo do que ocorreu em outros estados (SOLHA, 2004). A percepção dos diferentes governos sobre o que deveria compreender essa estrutura pública, sobre o nível de responsabilidade que deveria ter, vai incidir diretamente sobre o desenvolvimento ou não da atividade turística no estado, refletindo o seu nível de prioridade no conjunto da política estadual.

Reconhece-se aqui que, depois de 1999 - quando a Lei no 13.550/1999 recria uma nova estrutura para coordenar a política estadual de turismo, por meio da Agetur e do PPA, que também se estende ao turismo

18 Não é desconhecida a larga ajuda do estado de Goiás para seus artistas sertanejos. Consoante informações de O Popular (PULCINELI, 2013), de todos os contratados para shows, os artistas que mais receberam em 2014 foram Israel e Rodolfo (R\$ 1.874.095,00), Leonardo $(R \$ 1.080 .000,00)$ e João Neto e Frederico ( $R \$ 1.000 .000,00)$, todos sertanejos e goianos.

19 Nesta gestão foi criada a Empresa de Turismo do Estado de Goiás (Goiastur), via Lei n ${ }^{\circ} 7.540$, de 12 de setembro de 1972. Para mais entendimento sobre a Política Estadual de Turismo que antecede os anos 1990, consultar o estudo de doutorado da autora intitulado (2015).

20 Solha (2004) relata que o primeiro órgão público de turismo fundado em nível municipal, o de Salvador, surgiu em 1953, e que, dos 21 organismos estaduais, sete foram criados na década de 1970, sete na década de 1990 e os outros sete somente entre 2000 e 2003. 
-, o setor passa a ter traçados mais claros e uma pasta mais sólida. O panorama no País, como ressalta Solha (2004), é de retomada do desenvolvimento turístico, de acaloramento de ânimos dos empresários, de criação de cursos superiores e de impressão de maior confiança no setor pela sociedade. Isso foi o que ocorreu em Goiás e perdurou por uma década. No entanto, não se pode deixar de destacar que, atualmente, sente-se novamente um esmaecimento da vontade política, um apagar de luzes, sobretudo quando se trata do papel que deveria desempenhar o organismo público estadual nos tempos hodiernos de descentralização de ações e responsabilidades.

Em entrevistas realizadas com os secretários de Turismo de alguns dos principais municípios turísticos do estado, apreendeu-se uma falta de prioridade ou um ambiente de incerteza quanto à existência de uma política estadual de turismo no presente. Os secretários de Caldas Novas e Pirenópolis assim definiram a situação do turismo no estado:

O turismo não chama tanta atenção do governo no ambiente de agropecuária consolidado. Essas frentes são muito poderosas. Você tem que espernear muito pra conseguir algo. Por que o Nordeste é muito poderoso? Ele tem, no turismo, o seu melhor produto. Nós temos outras frentes bem consolidadas no estado. (Entrevista com o secretário de Turismo de Caldas Novas, em maio de 2015).

Nós trabalhamos acompanhando a política nacional e a estadual. O estado não tem nenhuma política específica atualmente, a gente sente que falta muito. A gente não responde pelo que tá ou não sendo feito pela Goiás Turismo. Quem impacta aqui, de fato, em termos de políticas públicas, é o governo federal, sem sombra de dúvida. [...] Do estado a gente recebe apoio na divulgação. O que já é de grande importância para o município. (Entrevista com o secretário de Turismo de Pirenópolis, em março de 2015).

Como confirma Solha (2004), verifica-se, porém, grande dificuldade para tornar realidade a participação dos estados na condução de uma política de fato do turismo, principalmente quando faltam ações que estimulem e criem um ambiente propício para provocar a independência dos organismos estaduais.

\section{CONSIDERAÇÕES FINAIS}

A partir de meados da década de 1990, o desenvolvimento do turismo no estado de Goiás foi dirigido, sobretudo, por programas do governo federal como o PED e o PNMT, cujas estratégias de gestão permitiram descentralizar as ações, repassando as decisões aos municípios turísticos e dando uma nova configuração para a política de gestão. Esses programas ajudaram a qualificar e formatar destinos goianos com perfil para o ecoturismo, algo que passou a ser uma identidade para o turismo estadual dali por diante. Já a fase do PRT coincidiu com uma maior racionalidade na gestão pública do turismo e a construção relativa da autonomia no planejamento e na gestão do turismo pelos municípios, fruto do amadurecimento do PPA como ferramenta.

A despeito das intervenções federais no turismo goiano nesse período retratado e da inserção de quatro destinos goianos na composição dos 65 destinos indutores do desenvolvimento do turismo regional, a atividade turística goiana não reverberou alterações significativas quanto ao seu valor econômico e aumento dos fluxos para o estado e a região, de modo a alcançar a desejada desconcentração da atividade turística no Brasil.

No que tange ao nível de organização do sistema de gestão estadual de turismo, ficou clara a perda recente do papel desempenhado pela Secretaria Estadual de Turismo, a Goiás Turismo, que levou à desmotivação da participação dos secretários municipais nos fóruns regionais. Notou-se uma crise institucional vivida 
pelo órgão de regulação máxima da atividade no estado, crise essa que resultou na perda de orientação de uma política integral para o turismo, uma vez que o órgão concentra seus esforços e recursos na realização de eventos, justificados pelas intercorrências do fator estacional da maior parte dos destinos turísticos do estado, o que confirma o descompasso da política de turismo.

Um dos maiores desafios na condução da Política Estadual de Turismo que se apresentou nessa trajetória de 23 anos, certamente, está associado ao fato de o turismo não representar uma área prioritária de investimentos no estado, sobretudo quando se considera o peso de outros setores produtivos, como o da indústria e da agropecuária, mesmo constatando-se que ocorreram mudanças importantes desde meados de 1990, capazes de significar um diferencial nas questões relacionadas ao planejamento estadual e municipal do turismo goiano.

\section{REFERÊNCIAS}

ALMEIDA, M. G. de. Políticas públicas e o delineamento do espaço turístico goiano. In: (Org.). Abordagens geográficas de Goiás. Goiânia: Ed. UFG, 2002. p. 197-222.

BRASIL. Ministério do Interior. Superintendência do Desenvolvimento do Centro-Oeste (Sudeco). Plano de desenvolvimento da Região Centro-Oeste. Brasília, DF, 1986.

CARVALHO, G. L. Mapeamento e trajetória político-institucional do turismo no estado de Goiás entre 1961 e 1990. Boletim Goiano de Geografia, Goiânia, v. 35, n. 3, p. 507-529, Set./Dez. 2015.

CRUZ, R. de C. A. Política de turismo e território. São Paulo: Contexto, 2000.

GOIÁS. Lei $\mathbf{n}^{\circ} \mathbf{7 . 5 4 0}$, de 12 de setembro de 1972. Define a política estadual de Turismo, o Contur e a Empresa de Turismo do Estado de Goiás e dá outras providências. Gabinete Civil da Governadoria, Goiânia, 1972. Disponível em: 〈http://www.gabinetecivil.goias.gov.br/leis_ordinarias/1972/ lei_7540.htm>.

GOIÁS. Lei no 11.655, de 26 de dezembro de 1991. Dispõe sobre a estrutura organizacional básica do Poder Executivo e dá outras providências. Gabinete Civil da Governadoria, Goiânia, 1991. Disponível em: 〈http://www.gabinetecivil.goias.gov.br/leis_ordinarias/1991/lei_11655.htm〉.

GOIÁS. Decreto no 4.112, de 14 de dezembro de 1993. Institui a Comissão para Condução, Gerenciamento e Apreciação do Zoneamento Ecológico-Econômico do Estado de Goiás. Gabinete Civil da Governadoria, Goiânia, 1993. Disponível em: 〈http://www.gabinetecivil.goias.gov.br/decretos/ numerados/1993/decreto_4112.htm>.

GOIÁS. Lei no 12.612 , de 17 de abril de 1995. Cria a empresa estadual que especifica. Gabinete Civil da Governadoria, Goiânia, 1995a. Disponível em: 〈http://www.gabinetecivil.goias.gov.br/leis_ ordinarias/1995/lei_12612.htm>.

GOIÁS. Decreto no 4.496, de 18 de julho de 1995. Institui a Comissão para Condução, Gerenciamento e Apreciação do Zoneamento Ecológico-Econômico do Estado de Goiás. Gabinete Civil da Governadoria, Goiânia, 1995b. Disponível em: 〈http://www.gabinetecivil.goias.gov.br/decretos/numerados/1995/ decreto_4496.htm>.

GOIÁS. Plano Plurianual 1996/1999. Goiânia: Seplan, 1996. 
GOIÁS. Decreto no 5.049, de 18 de maio de 1999. Cria o Comitê Executivo do Estado de Goiás, para o Programa Nacional de Municipalização do Turismo e dá outras providências. Gabinete Civil da Governadoria, Goiânia, 1999a. Disponível em: 〈http://www.gabinetecivil.goias.gov.br/decretos/ numerados/1999/decreto_5049.htm>.

GOIÁS. Decreto no $\mathbf{5 . 0 9 0}$, de 20 de agosto de 1999. Aprova o Estatuto da Agência de Turismo do Estado de Goiás - Agetur. Gabinete Civil da Governadoria, Goiânia, 1999b. Disponível em: 〈http:// www.gabinetecivil.goias.gov.br/decretos/numerados/1999/decreto_5090.htm>.

GOIÁS. Lei no 13.550, de 11 de novembro de 1999. Modifica a organização administrativa do Poder Executivo e dá outras providências. Gabinete Civil da Governadoria, Goiânia, 1999c. Disponível em: 〈http://www.gabinetecivil.goias.gov.br/leis_ordinarias/1999/lei_13550.htm〉.

GOIÁS. Lei Complementar no 13.570, de 28 de dezembro de 1999. Estabelece o Plano Plurianual para o período 2000-2003 e dá outras providências. Gabinete Civil da Governadoria, Goiânia, 1999d. Disponível em: 〈http://www.gabinetecivil.goias.gov.br/leis_ordinarias/1999/lei_13570.htm〉.

GOIÁS. Decreto n ${ }^{\mathbf{5}} \mathbf{3 0 0}$, de 18 de outubro de 2000. Dispõe sobre a política estadual de turismo e dá outras providências. Gabinete Civil da Governadoria, Goiânia, 2000a. Disponível em: 〈http://www. gabinetecivil.goias.gov.br/decretos/numerados/2000/decreto_5300.htm>.

GOIÁS. Plano Plurianual 2000/2003: Goiás século XXI. Goiânia: Seplan, 200ob.

GOIÁS. Plano Plurianual 2004/2007: Plano Goiás século XXI - Avançar Mais. Goiânia: Seplan, 2003.

GOIÁS. Lei no 14.769, de 12 de maio de 2004. Dispõe sobre a Política de Desenvolvimento do Ecoturismo e do Turismo Sustentável no Estado de Goiás. Gabinete Civil da Governadoria, Goiânia, 2004. Disponível em: 〈http://www.gabinetecivil.goias.gov.br/leis_ordinarias/2004/lei_14769.htm〉.

GOIÁS. Lei no 16.193, de 29 de janeiro de 2008. Dispõe sobre o Plano Plurianual para o quadriênio 20082011. Gabinete Civil da Governadoria, Goiânia, 2008a. Disponível em: 〈http://www.gabinetecivil. goias.gov.br/leis_ordinarias/2008/lei_16193.htm〉.

GOIÁS. Plano Plurianual 2008/2011: Goiás, estado de qualidade de vida. Goiânia: Seplan, 2008b.

GOIÁS. Lei de no $\mathbf{1 6 . 8 2 8}$, de 11 de dezembro de 2009. Cria a unidade básica, altera a nomenclatura e topologia das unidades complementares que especifica, da Goiás Turismo - Agência Estadual de Turismo - e altera a Lei no 16.272, de 30 de maio de 2008. Gabinete Civil da Governadoria, Goiânia, 2009. Disponível em:〈http://www.gabinetecivil.goias.gov.br/leis_ordinarias/2009/lei_16828.htm〉.

GOIÁS. Lei no $\mathbf{1 6 . 8 7 1}$, de 4 de janeiro de 2010. Dispõe sobre a revisão do Plano Plurianual 2008/2011, instituído pela Lei no 16.193 , de 29 de janeiro de 2008, para vigorar no biênio 2010/2011. Gabinete Civil da Governadoria, Goiânia, 2010a. Disponivel em: 〈http://www.gabinetecivil.goias.gov.br/leis_ ordinarias/2010/lei_16871.htm>.

GOIÁS. Lei no 17.140, de 1을 de setembro de 2010. Autoriza o Poder Executivo a contratar operação de crédito externa junto ao Banco Interamericano de Desenvolvimento - BID, no âmbito da Linha de Crédito do Prodetur, e dá outras providências. Gabinete Civil da Governadoria, Goiânia, 2010b. Disponível em: 〈http://www.gabinetecivil.goias.gov.br/leis_ordinarias/2010/lei_17140.htm〉.

GOIÁS. Lei no 17.257, de 25 de janeiro de 2011. Dispõe sobre a organização administrativa do Poder Executivo e dá outras providências. Gabinete Civil da Governadoria, Goiânia, 2011a. Disponível em: 〈http://www.gabinetecivil.goias.gov.br/leis_ordinarias/2011/lei_17257.htm〉. 
GOIÁS. Decreto no 7.351, de 25 de maio de 2011. Institui o Programa Estadual de Incentivo à Aviação Regional - Voe Goiás - e dá outras providências. Gabinete Civil da Governadoria, Goiânia, 2011b. Disponivel em: 〈http://www.gabinetecivil.goias.gov.br/decretos/numerados/2011/decreto_7351. htm>.

GOIÁS. Plano de Ação Integrada de Desenvolvimento (PAI) 2012-2015. Goiânia: Segplan, 2012.

GOIÁS TRANSPARENTE. Relatórios da Lei de Responsabilidade Fiscal. [2015]. Disponível em: 〈http:// www.transparencia.go.gov.br/pagina.php?id=19>.

GOIÁS TURISMO. Plano Estadual de Turismo: Goiás no caminho da inclusão. Goiânia, 2007.

GOIÁS TURISMO. Dossiê de ações: Prodetur Goiás - jul./2011 a out./2012. Goiânia, 2012.

INSTITUTO BRASILEIRO DE GEOGRAFIA E ESTATÍSTICA. Contagem da População: 1996. Rio de Janeiro, 1996. Disponível em: 〈http://www.ibge.gov.br/home/estatistica/populacao/contagem〉.

INSTITUTO BRASILEIRO DE TURISMO. Deliberação Normativa nํ 385, de 28 de novembro de 1997. Diário Oficial da República Federativa do Brasil, Seção 1, n. 236, 5 dez. 1997.

INSTITUTO BRASILEIRO DE TURISMO. Procedimentos do Programa Nacional de Municipalização do Turismo (PNMT). Brasília, DF, 1999a.

INSTITUTO BRASILEIRO DE TURISMO. Deliberação Normativa nํ 408, de 3 de agosto de 1999. Diário Oficial da República Federativa do Brasil, Seção 1, n. 154, 12 ago. 1999b.

INSTITUTO BRASILEIRO DE TURISMO. Deliberação Normativa nํ 417, de 13 de dezembro de 2000. Diário Oficial da República Federativa do Brasil, Seção 1, n. 13, 18 jan. 2001.

INSTITUTO BRASILEIRO DE TURISMO. Deliberação Normativa nํ 432, de 28 de novembro de 2002. Diário Oficial da República Federativa do Brasil, Seção 1, 3 dez. 2002.

PULCINELI, F. Crescem gastos com shows. 0 Popular, Goiânia, 18 ago. 2013. Caderno Cidades.

SALGADO, T. R. Planejamento e regionalização: análise dos Planos Plurianuais elaborados pelo Governo do Estado de Goiás entre 1999 e 2007. 2010. 138 f. Dissertação (Mestrado em Geografia) Instituto de Estudos Socioambientais, Universidade Federal de Goiás, Goiânia, 2010.

SOLHA, K. T. Órgãos públicos estaduais e o desenvolvimento do turismo no Brasil. 2004. $168 \mathrm{f}$. Tese (Doutorado em Relações Públicas, Propaganda e Turismo) - Escola de Comunicação e Artes, Universidade de São Paulo, São Paulo, 2004. 